\title{
Bisphosphonates and BMU birth rate
}

\author{
S. M. Ott
}

Received: 8 March 2009 / Accepted: 22 June 2009 / Published online: 1 August 2009

(C) International Osteoporosis Foundation and National Osteoporosis Foundation 2009

Keyword Bisphosphonate $\cdot$ BMU

In his essay about stopping anti-resorptive therapy, Seeman [1] states that anti-resorptive medications "reduce the birth rate of BMUs". I do not think this is correct. A BMU travels along the surface of the bone, or drills through the cortical bone, for a long time, 2-8 months. At any particular spot on the bone surface, the BMU is active for about 3 months. If medications merely reduced the birth rate of BMUs, then there would be a gradual decrease in bone resorption that would last for months until a steady state low level was reached, and an even longer rate of decline in the bone formation rates. What is seen, however, is a rapid decrease in bone resorption in a few weeks and a decrease in the bone formation rate that lasts about as long as the formation period before reaching a lower plateau level. This timing is more consistent with an action that reduces the ability of the osteoclasts to resorb bone [2]. For bisphosphonates, this is also consistent with the mechanism of action on the molecular level, which is to inhibit farnesyl pyrophosphate synthase, thereby stopping resorption, whether it is occurring early in the formation of a BMU or as the BMU is progressing along its course.
Once bisphosphonates have been given, the factors that initiate BMUs (micro-trauma, for example) are still present, but without functioning osteoclasts the frustrated BMU will not be able to resorb bone or to travel along the surface; without bone resorption, there will be no bone formation either. This accounts for the decreased bone formation as well as the accumulation of microdamage that is seen on biopsies of patients on long-term treatment [3].

Conflicts of interest None.

\section{References}

1. Seeman E (2009) To stop or not to stop, that is the question. Osteoporos Int 20:187-195. doi:10.1007/s00198-008-0813-x

2. Ott SM (2002) Histomorphometric analysis of bone remodeling. In: Bilezikian JP, Raisz LG, Rodan GA (eds) Principles of bone biology. Academic Press, San Diego, CA, pp 303-320

3. Stepan JJ, Burr DB, Pavo I, Sipos A, Michalska D, Li J et al (2007) Low bone mineral density is associated with bone microdamage accumulation in postmenopausal women with osteoporosis. Bone $41: 378-385$

A reply to this letter can be found at doi 10.1007/s00198-009-1027-6.

S. M. Ott $(\bowtie)$

University of Washington,

Box 356426, Seattle, WA 98195, USA

e-mail: smott@u.washington.edu 